\title{
Total Costs and Atrial Fibrillation Ablation Success or Failure in Medicare-Aged Patients in the United States
}

Michael H. Kim · Jay Lin · Charles Kreilick · Susan H. Foltz Boklage

Received: June 17, 2010 / Published online: August 9, 2010

(c) The Author(s) 2010. This article is published with open access at Springerlink.com

\section{ABSTRACT}

Introduction: This retrospective cohort study compared the direct medical costs of successful versus unsuccessful catheter ablation in Medicareaged patients with atrial fibrillation (AF), using medical claims data. Methods: AF patients with $\geq 12$ months of continuous medical/pharmacy coverage pre- and postablation were identified from the MarketScan ${ }^{\circledR}$ Medicare database (January 2003 to December 2006). For study inclusion, patients were required to have $\geq 2 \mathrm{AF}$ inpatient/outpatient visits within 6 months and to have received antiarrhythmic drug therapy within 12 months prior to the index ablation. Ablation success was defined as the absence

Michael H. Kim $(\bowtie)$

Division of Cardiology, Northwestern University,

Feinberg School of Medicine, 251 E. Huron St., Feinberg

Pavilion, Suite 8-503, Chicago, IL 60611, USA.

Email: michael.kim@nmff.org

Jay Lin

sanofi-aventis, Bridgewater, NJ, USA

Charles Kreilick

ProUnlimited, Boca Raton, FL, USA

Susan H. Foltz Boklage

ProUnlimited, Boca Raton, FL, USA of antiarrhythmic drug therapy 6-12 months postablation. Results: Of 135 patients identified (67\% men, mean age 73 years), ablation was successful in 69 (51.1\%); most patients (96\%) underwent a single procedure. Patients with successful ablation discontinued antiarrhythmic drug treatment after (mean) 54 days. Use of rate-control and anticoagulant drugs decreased after successful ablation, from $87 \%$ to $67 \%$ and from $86 \%$ to $64 \%$ of patients, respectively. Among failed ablation patients, $74 \%$ versus $70 \%$ received rate-control drugs, and $88 \%$ versus $82 \%$ received anticoagulants pre- versus postablation. Mean \pm SD per-patient procedural costs were $\$ 13,655 \pm \$ 12,761$ for successful compared with $\$ 17,294 \pm \$ 26,502(P=0.21)$ for failed ablation, while AF-related medical costs over 12 months postablation were $\$ 2394 \pm \$ 642$ and $\$ 2703 \pm \$ 1706$, respectively $(P<0.001)$. Overall costs tended to be lower for successful $(\$ 16,049 \pm \$ 12,536)$ than for failed $(\$ 19,997 \pm \$ 13,958)$ AF ablation $(P=0.07)$. These findings are subject to the limitations imposed by a retrospective database analysis and a small sample size. Conclusion: Outside the clinical-trial setting, catheter ablation for second-line treatment of AF proved unsuccessful in half of Medicare-aged patients. Direct medical costs did not differ significantly between 
patients with failed and successful ablations. The high rate and costs of AF ablation failure in the Medicare-aged population reinforce the need for better understanding of prognostic factors for ablation outcome.

Keywords: arrhythmia; atrial fibrillation; catheter ablation; cohort study; costs; elderly; Medicare

\section{INTRODUCTION}

Atrial fibrillation (AF) is the most frequently encountered arrhythmia in clinical practice, affecting an estimated 3 million adults in the US. ${ }^{1}$ The condition is predominantly a disease of the elderly, increasing in prevalence from $\sim 0.1 \%$ in the adult population under 55 years of age to $6 \%$ in those over 65 years and to $8 \%-10 \%$ in those over 80 years. ${ }^{2,3}$ Accordingly, the burden of AF is borne overwhelmingly by the Medicare-aged population, with an estimated $82 \%$ of cases occurring in the 65 - to 85-year age group. ${ }^{3} \mathrm{AF}$ is an established risk factor for cerebral thromboembolism and heart failure, ${ }^{4,5}$ and hospitalization and mortality rates for $\mathrm{AF}$ have risen significantly in recent decades. ${ }^{6-8}$ Consequently, the economic impact of AF is substantial, amounting to an estimated $\$ 6-\$ 7$ billion per annum in direct medical expenditure in the US, with the primary cost driver being hospitalization. ${ }^{9,10}$

Clinical management of AF has three principal objectives-control of ventricular rate, maintenance of sinus rhythm, and prevention of thromboembolism. ${ }^{11}$ In view of the potential toxicity and limited efficacy of current Class I and III antiarrhythmic drugs, nonpharmacologic techniques are increasingly being applied for rhythm control in AF. Radiofrequency catheter ablation of AF has evolved rapidly over the past decade and is now a routine procedure in most major medical centers. ${ }^{12,13}$ In selected patient populations, catheter ablation has demonstrated superiority over antiarrhythmic drug therapy in maintaining sinus rhythm, improving symptoms, and preventing hospitalization for AF. ${ }^{14}$ As a potentially curative procedure, catheter ablation offers the prospect of reducing the longterm healthcare costs of AF by avoiding repeat episodes of hospitalization. ${ }^{15,16}$

In recent years, the patient population undergoing catheter ablation for AF has become progressively older, with more persistent $\mathrm{AF}$ and more advanced structural heart disease. ${ }^{17}$ However, there is relatively little published literature on the clinical and economic outcomes of AF ablation therapy in the Medicare-aged population outside the controlled environment of clinical trials. Using a medical claims database, the present study was undertaken to determine the perceived success rate of catheter ablation in Medicare-aged patients with $\mathrm{AF}$, and to compare medical costs between patients with successful and failed ablation procedures in the "real world" (ie, nonclinical-trial) setting.

\section{MATERIALS AND METHODS}

\section{Study Design}

This retrospective cohort study utilized data from the proprietary MedStat MarketScan ${ }^{\circledR}$ Medicare Supplemental and Coordination of Benefits database for the period between January 2003 and June 2007. The MarketScan databases are derived from employer or government-funded (Medicare) healthcare insurance plans and include information on 21.6 million individuals of all ages covered under a variety of fee-forservice and capitated provider reimbursement schemes. MarketScan has formed the basis of more than 250 peer-reviewed publications published over the last 20 years. ${ }^{18,19}$ Diagnostic 
information was identified using International Classification of Diseases, Ninth Revision, Clinical Modification (ICD-9-CM) codes, and procedures were identified. In compliance with the Health Insurance Portability and Accountability Act of 1996 (HIPAA), all patient data used in this study were de-identified and thus Institutional Review Board approval was not required.

\section{Sample Selection}

Men and women aged $\geq 19$ years who were diagnosed with AF (ICD-9-CM code 427.31) in an inpatient setting between January 2004 and January 2005, and who additionally underwent an intracardiac catheter ablation procedure for treatment of supraventricular tachycardia (Current Procedural Terminology [CPT] code 93651: intracardiac catheter ablation of arrhythmogenic focus; for treatment of supraventricular tachycardia by ablation of fast or slow atrioventricular pathways, accessory atrioventricular connections or other atrial foci, singly or in combination) between January 2004 and December 2005, were identified. Patients were required to have undergone catheter ablation within 6 months of their qualifying AF diagnosis (the first ablation procedure was designated as index), and to have continuous medical/ pharmacy coverage for the 12-month period immediately before and after the index ablation. To control for catheter ablation procedures unrelated to $\mathrm{AF}$, patients were excluded if they had an ICD-9-CM diagnosis code for paroxysmal supraventricular tachycardia (427.0) or other (unspecified) supraventricular tachycardias (427.89) within the 12-month pre-index period. To ensure that patients were being actively managed for AF, they were required to have had two or more office visits or hospitalizations for AF within the 6-month period preceding the index ablation. Furthermore, in line with current recommendations that ablation should be reserved for use as a second-line treatment option in $\mathrm{AF}^{11,20}$ patients were required to have a claim submission for antiarrhythmic medication during the 12-month period prior to the index ablation.

\section{Outcome Measures}

For the purpose of this analysis, ablation success was defined as the absence of antiarrhythmic drug therapy during the period 6-12 months postablation. In the event that a patient provided evidence of having undergone a repeat ablation procedure(s) within 6 months of the first (index) procedure, success rates were determined for the "first ablation" and "all ablations." Since suppressive antiarrhythmic drug therapy is commonly employed in the early postablation phase, ${ }^{20}$ antiarrhythmic use during the period 0-5 months following the ablation procedure was not taken into consideration in determining ablation outcome.

In evaluating medical resource utilization, direct medical costs were summarized for: (1) hospitalizations involving the ablation procedure(s); (2) other inpatient/outpatient medical services; and (3) drug treatment over the 12 months following the index ablation.

\section{Statistical Analysis}

Statistical analyses were conducted using the $\mathrm{SAS}{ }^{\circledR}$ System version 9.1.3 (SAS Institute Inc., Cary, NC, USA). Categorical results were compared using the $\chi^{2}$ test for significance. To determine statistical differences in costs, logtransformed direct costs were compared between the ablation success and failure groups using Student's $t$-test. A probability value of $P \leq 0.05$ was considered statistically significant. Data are expressed as mean \pm standard deviation (SD). 


\section{RESULTS}

\section{Study Population}

Of a total of 1022 patients identified in the database as having undergone a catheter ablation procedure for AF at a specialist medical center during the specified study period, 135 patients satisfied all the study eligibility criteria and were included in the analysis (Figure 1). Baseline demographic characteristics and comorbidities of these patients are summarized in Table 1. Overall, the mean age of the study population was $73 \pm 5.4$ years and two-thirds of patients were male. A high proportion of patients had cardiovascular comorbidities-most commonly coronary artery disease (54.1\%), hypertension $(43.7 \%)$, valvular heart disease (34.8\%), and congestive heart failure (26.7\%). Prior to the index ablation, all patients had received antiarrhythmic drug therapy for

Figure 1. Patient identification and selection. ${ }^{*} 74$ of 209 patients who met the study's data requirements underwent catheter ablation without satisfying currently accepted guideline recommendations for use of this procedure (ie, demonstrated refractoriness or intolerance to $\geq 1$ Class Ic or III antiarrhythmic drugs). Ablation outcomes based on prescription claims data could not be determined for these patients. AF=atrial fibrillation; PSVT=paroxysmal supraventricular tachycardia (International Classification of Diseases, Ninth Revision, Clinical Modification [ICD-9-CM] diagnosis code 427.0).

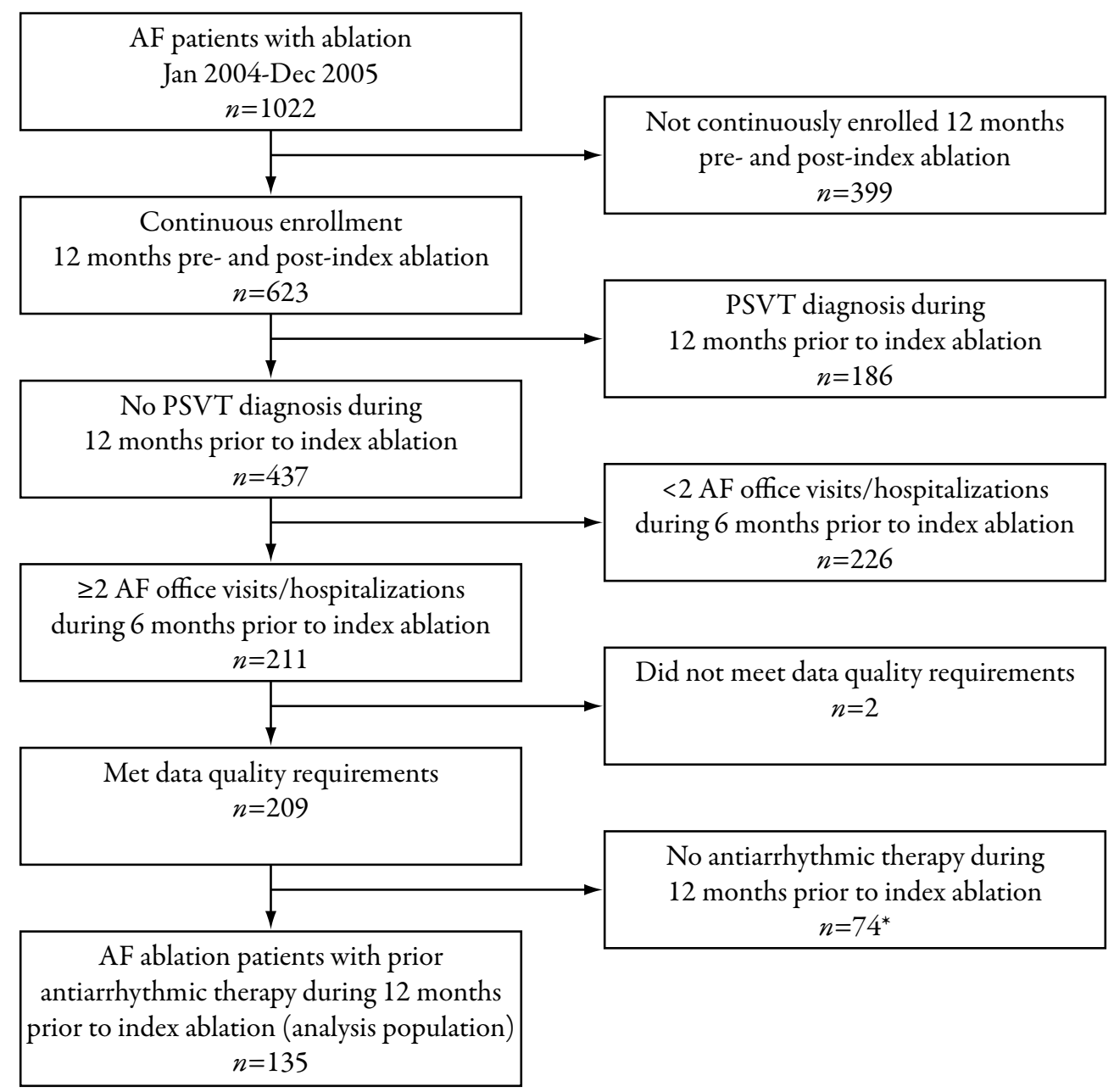


Table 1. Patient baseline demographic characteristics and comorbidities.

\begin{tabular}{|c|c|c|c|c|}
\hline Characteristic & $\begin{array}{c}\text { Total } \\
(n=135)\end{array}$ & $\begin{array}{l}\text { Ablation success } \\
\qquad(n=69)\end{array}$ & $\begin{array}{l}\text { Ablation failure } \\
\qquad(n=66)\end{array}$ & $P$ value \\
\hline Male, $n(\%)$ & $91(67.4)$ & $45(65.2)$ & $46(69.7)$ & 0.58 \\
\hline Age, years, mean $\pm S D$ & $73.0 \pm 5.4$ & $73.2 \pm 5.0$ & $72.8 \pm 5.8$ & 0.66 \\
\hline \multicolumn{5}{|l|}{ Age category, $n(\%)$} \\
\hline 55-64 years & $1(0.7)$ & 0 & $1(1.5)$ & \\
\hline $65-74$ years & $86(63.7)$ & $45(65.2)$ & $41(62.1)$ & \\
\hline$\geq 75$ years & $48(35.6)$ & $24(34.8)$ & $24(36.4)$ & \\
\hline Payer type, $n(\%)$ & & & & 0.63 \\
\hline Medicare Fee for Service & $121(89.6)$ & $61(88.4)$ & $60(90.9)$ & \\
\hline Medicare Encounter & $14(10.4)$ & $8(11.6)$ & $6(9.1)$ & \\
\hline Geographic region, $n(\%)$ & & & & 0.86 \\
\hline North east & $11(8.1)$ & $5(7.2)$ & $6(9.1)$ & \\
\hline North central & $66(48.9)$ & $33(47.8)$ & $33(50.0)$ & \\
\hline South & $36(26.7)$ & $18(26.1)$ & $18(27.3)$ & \\
\hline West & $22(16.3)$ & $13(18.8)$ & $9(13.6)$ & \\
\hline \multicolumn{5}{|l|}{ Comorbidities, $n(\%)$} \\
\hline Ischemic stroke & $4(3.0)$ & $2(2.9)$ & $2(3.0)$ & 0.96 \\
\hline Congestive heart failure & $36(26.7)$ & $19(27.5)$ & $17(25.8)$ & 0.82 \\
\hline Valvular heart disease & $47(34.8)$ & $27(39.1)$ & $20(30.3)$ & 0.28 \\
\hline Coronary artery disease & $73(54.1)$ & $44(63.8)$ & $29(43.9)$ & 0.02 \\
\hline Peripheral vascular disease & $10(7.4)$ & $7(10.1)$ & $3(4.5)$ & 0.21 \\
\hline Cardiomyopathy & $15(11.1)$ & $8(11.6)$ & $7(10.6)$ & 0.86 \\
\hline Pulmonary disease & $35(25.9)$ & $22(31.9)$ & $13(19.7)$ & 0.11 \\
\hline Thyroid disease & $14(10.4)$ & $3(4.3)$ & $11(16.7)$ & 0.02 \\
\hline Diabetes & $21(15.6)$ & $15(21.7)$ & $6(9.1)$ & 0.04 \\
\hline Hypertension & $59(43.7)$ & $29(42.0)$ & $30(45.5)$ & 0.69 \\
\hline Charlson Comorbidity Index, mean $\pm S D$ & $1.5 \pm 1.6$ & $1.8 \pm 1.8$ & $1.3 \pm 1.4$ & 0.09 \\
\hline
\end{tabular}

rhythm control, most frequently amiodarone (49.6\%), sotalol (31.9\%), dofetilide $(14.1 \%)$, and propafenone $(14.1 \%)$. Most patients had received drug treatment for ventricular rate control $(80.7 \%)$, primarily beta-blockers (63.7\% of all patients), and calcium channel blockers $(39.3 \%)$, as well as anticoagulant therapy $(86.7 \%)$, most commonly warfarin (85.9\% of all patients). A small minority of patients had additionally received antiplatelet drug therapy (11.9\%).
Catheter ablation was judged to have been successful, according to the study criterion, in 69 patients (51.1\% of the study population) and unsuccessful in 66 patients $(48.9 \%)$. The two patient subgroups ("ablation success" group and "ablation failure" group) were generally well matched in terms of baseline demographic and clinical characteristics, geographic distribution, and healthcare provision (Table 1). Preablation use of ratecontrol agents, anticoagulants, and antiplatelet 
drugs did not differ significantly between the two groups.

\section{Ablation Procedures and Clinical Outcomes}

Most patients (97\% with successful ablation and $94 \%$ with failed ablation, as defined according to the study criterion) underwent only one ablation procedure during the study period. For those patients undergoing a repeat procedure (two patients in the "ablation success" group and four patients in the "ablation failure" group), this was performed 5.1-12.0 months after the index event. All ablation procedures were conducted in the inpatient setting, and the mean length of stay per procedure was $2.5 \pm 3.2$ days for patients with successful ablation and $2.3 \pm 2.3$ days for those with failed ablation (median 1.0 day for each group).

After successful ablation, patients discontinued antiarrhythmic drug therapy within 53.6 \pm 48.1 days, compared with $238 \pm 103$ days after failed ablation (by definition, patients with failed ablation remained on antiarrhythmic drug therapy for at least 6 months following the procedure). Use of adjunctive drug therapy for AF also declined after successful ablation: from $87 \%$ of patients preablation to $67 \%$ at $6-12$ months postablation for rate-control drugs, from $86 \%$ to $64 \%$ of patients for anticoagulants, and from $16 \%$ to $4 \%$ of patients for antiplatelet drugs. In contrast, for patients with failed ablation the use of these agents did not change appreciably between the pre- and postablation periods: from $74 \%$ to $70 \%$ for rate-control drugs, and from $88 \%$ to $82 \%$ for anticoagulants, while $7.6 \%$ of patients received antiplatelet drugs both pre- and postablation. During the postablation period, there were no significant differences in individual comorbidity frequencies between patients with successful and failed ablation procedures.

\section{Direct Medical Costs Associated with Ablation and AF Management}

The mean cost per ablation procedure was $\$ 13,270 \pm \$ 12,139$ for patients with successful ablation compared with $\$ 16,306 \pm \$ 25,315$ for patients with failed ablation $(P=0.24)$. Similarly, the mean ablation cost per patient tended to be lower for patients with successful ablation $(\$ 13,655 \pm \$ 12,761)$ than for those with failed ablation $(\$ 17,294 \pm \$ 26,502 ; P=0.21)$. In contrast, median ablation costs differed only marginally between the "ablation success" and "ablation failure" groups (cost per procedure: $\$ 11,930$ vs. $\$ 11,643$, respectively; cost per patient: $\$ 11,795$ vs. $\$ 11,778$, respectively). Subsequent AF-related medical costs (ie, costs for claims with a primary AF diagnosis) during the 12-month period following the index ablation were $\$ 2394 \pm \$ 642$ for patients with successful ablation versus $\$ 2703 \pm 1706$ for patients with failed ablation $(P<0.001)$. Successful ablation was associated with significantly lower pharmacy costs $(\$ 123 \pm \$ 43$ vs. $\$ 808 \pm \$ 625$; $P<0.0001)$ and outpatient costs $(\$ 763 \pm \$ 469$ vs. $\$ 1080 \pm \$ 657 ; P=0.02)$. On exclusion of pharmacy costs (a likely confounder, since patients with successful ablation by definition did not receive antiarrhythmic therapy), AF-related medical costs for the ablation success and failure groups were not dissimilar (\$2272 vs. \$1894 per patient, respectively; no statistical comparison available). Overall, the total annualized cost per patient of medical management of $\mathrm{AF}$ (ie, cost of ablation procedures plus other AF-related services) tended to be lower in patients with successful ablation than in those with failed ablation $(\$ 16,049 \pm \$ 12,536$ vs. $\$ 19,997 \pm \$ 13,958 ; P=0.07$ ) (Table 2 ). 
Table 2. Direct medical costs (US\$) associated with ablation and atrial fibrillation (AF) management.

\begin{tabular}{|c|c|c|c|c|}
\hline & $\begin{array}{l}\text { All patients } \\
(n=135)\end{array}$ & $\begin{array}{l}\text { Ablation success } \\
\qquad(n=69)\end{array}$ & $\begin{array}{l}\text { Ablation failure } \\
\qquad(n=66)\end{array}$ & $P$ value \\
\hline \multicolumn{5}{|c|}{ Cost per patient of inpatient ablation procedures } \\
\hline Mean \pm SD & $15,434 \pm 20,656$ & $13,655 \pm 12,760$ & $17,294 \pm 26,502$ & 0.21 \\
\hline Median & 11,795 & 11,795 & 11,778 & \\
\hline \multicolumn{5}{|c|}{ Subsequent AF-related costs per patient* } \\
\hline \multicolumn{5}{|l|}{ Inpatient $\dagger$} \\
\hline Mean \pm SD & $1031 \pm 6061$ & $1361 \pm 7509$ & $687 \pm 4063$ & 0.57 \\
\hline Median & 0 & 0 & 0 & \\
\hline \multicolumn{5}{|l|}{ Outpatient } \\
\hline Mean \pm SD & $918 \pm 1231$ & $763 \pm 1076$ & $1080 \pm 1364$ & 0.02 \\
\hline Median & 558 & 469 & 657 & \\
\hline \multicolumn{5}{|l|}{ Pharmacy } \\
\hline Mean $\pm S D$ & $458 \pm 660$ & $123 \pm 197$ & $808 \pm 784$ & $<0.0001$ \\
\hline Median & 216 & 43 & 625 & \\
\hline \multicolumn{5}{|l|}{ Laboratory } \\
\hline Mean \pm SD & $39 \pm 155$ & $44 \pm 157$ & $34 \pm 155$ & 0.74 \\
\hline Median & 0 & 0 & 0 & \\
\hline \multicolumn{5}{|l|}{ Emergency } \\
\hline Mean \pm SD & $11 \pm 66$ & $11 \pm 72$ & $10 \pm 60$ & 0.69 \\
\hline Median & 0 & 0 & 0 & \\
\hline \multicolumn{5}{|l|}{ Radiology } \\
\hline Mean \pm SD & $68 \pm 280$ & $81 \pm 322$ & $55 \pm 231$ & 1.00 \\
\hline Median & 0 & 0 & 0 & \\
\hline \multicolumn{5}{|l|}{ Ancillary/other } \\
\hline Mean $\pm S D$ & $20 \pm 69$ & $12 \pm 53$ & $28 \pm 82$ & 0.45 \\
\hline Median & 0 & 0 & 0 & \\
\hline \multicolumn{5}{|l|}{ Total } \\
\hline Mean \pm SD & $2545 \pm 6298$ & $2394 \pm 7677$ & $2703 \pm 4478$ & $<0.001$ \\
\hline Median & 1292 & 642 & 1706 & \\
\hline \multicolumn{5}{|c|}{ Total cost per patient } \\
\hline Mean \pm SD & $17,979 \pm 22,294$ & $16,049 \pm 17,135$ & $19,997 \pm 26,635$ & 0.07 \\
\hline Median & 13,518 & 12,536 & 13,958 & \\
\hline
\end{tabular}

*Includes costs for claims with a primary AF diagnosis only.

tCosts associated with the primary admission diagnosis of AF. 


\section{DISCUSSION}

Available evidence from clinical studies suggests that catheter-based ablation of AF offers benefit to selected patients who are resistant to pharmacologic or electrical conversion to sinus rhythm. ${ }^{11,20}$ Moreover, ablation therapy, either alone or with adjuvant antiarrhythmic drug therapy, appears to offer a comparable level of AF control in the elderly ( $>65$ years) to that achieved in younger patients. ${ }^{21-26}$ However, these studies provide no clear indication of absolute rates of treatment success: ablation outcomes vary considerably from study to study because of confounding factors such as differences in patient populations (eg, age, concomitant cardiac disease, pattern and duration of AF, antiarrhythmic drug use), duration of follow-up, frequency of arrhythmia monitoring, and definition of ablation success, as well as technical aspects of the procedure itself. ${ }^{20}$ Few randomized, double-blind studies of catheter ablation have been performed, and cohort studies have frequently lacked clear and prospectively defined outcomes. The ongoing Catheter Ablation Versus Antiarrhythmic Drug Therapy for Atrial Fibrillation (CABANA) pilot trial (NCT00578617), a randomized, openlabel comparison of catheter ablation versus pharmacotherapy for rate and rhythm control in $\mathrm{AF}$, is one of the few studies to enroll Medicareaged patients (up to 90 years of age).

Catheter ablation is currently recommended as a second-line treatment option for $\mathrm{AF}$, with its use reserved for symptomatic patients who are refractory or intolerant to at least one Class I or Class III antiarrhythmic agent. ${ }^{20}$ However, it would appear that the procedure is not infrequently employed in clinical practice as a viable firstline therapy for AF: in our study we excluded over one-third of otherwise eligible patients (74 out of 209) who provided no documented evidence of prior antiarrhythmic drug exposure. When catheter ablation is used in accordance with accepted guideline recommendations, the results of the study indicate that, in the "realworld" setting (ie, outside the controlled clinical trial), the procedure is successful, as defined by the absence of antiarrhythmic drug therapy at 6 months postablation, in approximately one-half of Medicare-aged patients with AF. This figure is consistent with the results of a worldwide survey (1995-2002) of the outcomes of nearly 9000 catheter ablation procedures performed for AF in a large and heterogenous population (age unspecified), which reported an antiarrhythmic drug-free success rate (ie, proportion of patients asymptomatic in the absence of any antiarrhythmic drug) of $52.0 \%$ over a (median) 12-month (range, 1-98 months) follow-up period. ${ }^{27}$ This result was achieved with $27 \%$ of patients requiring a second or third ablation procedure, which is considerably higher than the corresponding figure (4\%-5\%) in our Medicare-aged population. It should be noted that despite careful patient selection, there was marked variation in ablation efficacy between the various electrophysiology centers participating in the survey, with antiarrhythmic drug-free success rates ranging from $15 \%$ to $77 \% .{ }^{27}$ This variation in success rate appeared to be independent of ablation technique and AF type, suggesting that other factors, such as the use of repeat ablation procedures, physician experience, and the length of patient follow-up, may be important determinants of the efficacy of catheter ablation in clinical practice. ${ }^{27}$ It is recognized that catheter ablation for AF is not a genuinely curative procedure, and that AF may recur long ( $>1$ year) after completion of successful ablation, ${ }^{28-30}$ possibly on account of restoration of conduction across the lesion set. ${ }^{31}$ Long-term follow-up of patients who experience prolonged ( $\geq 1$ year) AF-free periods after successful catheter 
ablation has revealed appreciable attrition rates, with a $25 \%$ cumulative recurrence rate at 5 years postablation. ${ }^{30}$

Given the constraints of the available data in the present study, we were unable to determine ablation success in terms of symptom control or prevention of AF recurrence. In the absence of arrhythmia monitoring data, we instead defined ablation success as freedom from the need for continued antiarrhythmic drug therapy at 6 months postablation. One drawback of this approach is that it may potentially underestimate the true effectiveness of the AF ablation procedure, since the use of antiarrhythmic drug therapy postablation is not necessarily indicative of treatment failure. New-onset atrial tachycardias occur in up to $25 \%$ of patients following catheter ablation for $\mathrm{AF}^{32,33}$ and, although many of these arrhythmias are self-limiting and resolve spontaneously, prophylactic antiarrhythmic therapy is commonly administered for the first 1 to 3 months postablation. ${ }^{34}$ It should be recognized, however, that if a patient shows a good clinical response during this early phase, the physician may be reluctant to withdraw drug therapy to assess the clinical efficacy of the ablation procedure alone. This is particularly the case with elderly patients, who are more likely than their younger counterparts to remain on antiarrhythmic drug therapy beyond this initial period. ${ }^{26}$ Accordingly, some of the 66 patients who were receiving antiarrhythmic drug therapy at 6 months postablation may have undergone a successful ablation procedure, although the likelihood of achieving a completely successful result more than 6 months after the initial ablation is low. The majority of these cases likely represent ablation failures or attempts at "hybrid" therapy, with antiarrhythmic drugs being used in conjunction with the recent ablation procedure to control AF. It is well known that catheter ablation may be partially effective and allow a patient with AF, previously refractory to antiarrhythmic therapy, to become drug responsive. ${ }^{20}$ For these patients, drug therapy following ablation is an acceptable longterm management strategy, and often preferable to repeat ablation.

Previous economic evaluations of catheter ablation for AF have generally involved costeffectiveness comparisons with medical therapy. ${ }^{35-38}$ A Canadian study concluded that catheter ablation represented a fiscally sensible alternative to medical therapy in $\mathrm{AF}$, with ablation costs $(\sim \$ 16,000-\$ 21,000$, including costs of periprocedural medical care and complications) approximating to those of ongoing medical care after (mean) 4 years of follow-up. ${ }^{36}$ A more recent US study, using a disease-simulation Markov model (based on clinical trial, registry, and Medicare claims data) for a hypothetical cohort of patients with treatment-refractory paroxysmal $\mathrm{AF}$, concluded that, over a 5-year time-frame, the cumulative costs of catheter ablation with/ without adjunctive antiarrhythmic drug therapy $(\$ 25,584)$ would be marginally higher than those of ongoing medical therapy $(\$ 19,898)$, with cost neutrality being achieved after 10 years. ${ }^{38}$

The present study indicates that the direct medical costs of catheter ablation in Medicareaged patients with AF are comparable to those reported above, amounting to approximately $\$ 16,000-\$ 20,000$ (inclusive of the ablation procedure and other AF-related services) over the first 12 months postablation. Over the same period, an unsuccessful ablation procedure is, on average, approximately $\$ 4000$ more expensive than a successful one, partly on account of the significantly greater expenditure devoted to pharmacy and outpatient services. It should be noted, however, that this cost differential is likely exaggerated by the confounding influence of pharmacy costs, which (not unexpectedly) were higher in patients with unsuccessful 
ablation. With time, the cost differential might be expected to widen further if repeat ablations are performed following failure of the index ablation. As expected, the major cost component is represented by the ablation procedure and its associated hospitalization event. This composite cost tended to be higher for patients who subsequently experienced ablation failure rather than ablation success (mean, $\$ 16,306$ vs. $\$ 13,270$ per ablation procedure), although the large SDs $(\$ 25,315$ vs. $\$ 12,139$, respectively) would suggest that the mean costs were distorted by extreme outlying values, possibly as a result of procedural complications such as stroke, embolism, hemorrhage, tamponade, or pericardial drainage. Against this, the close similarity in median costs for the "ablation success" and "ablation failure" groups ( $\$ 11,643$ vs. \$11,930 per ablation procedure, respectively) would argue against major differences in complication patterns between the two patient groups. Nevertheless, the relatively high proportion of ablation failures identified in the Medicare-aged patient population with AF, coupled with the added outpatient costs associated with ablation failure, emphasizes the need for better understanding of prognostic factors for ablation outcome, since this would enable more targeted application.

In assessing the applicability of this economic analysis to clinical practice, several factors should be considered. The study was based on a limited patient sample drawn from specialist centers across the US over a 4-year period and, because of possible selection bias, caution is required in extrapolating these findings to the elderly AF ablation population in general. Latest figures indicate that the use of catheter ablation for treatment of AF in the Medicare population has risen markedly over the past decade, with the annual procedural volume increasing from 315 cases in 2001 to 1975 cases in 2006. ${ }^{39}$ Our exclusion of patients who showed no evidence of antiarrhythmic drug treatment in the 12 months immediately prior to ablation placed a possibly unnecessary constraint on study recruitment. It is possible that some of the elderly AF patients were referred for ablation several years after their original diagnosis, and that they may at some point have tried a rhythm-control strategy-but not within the 12 months prior to ablation, and for this reason they were not included in the analysis. Due to its retrospective, nonrandomized design, we cannot rule out confounding factors (whether related to the patients, the disease, the ablation procedure, or standard of medical care) that may have influenced the clinical outcomes and cost differences seen in this study. Importantly, information was lacking regarding arrhythmia duration and persistence (paroxysmal, persistent, or chronic)-two of the most powerful predictors of AF ablation success-among the patients in this study. The procedural code used for identification of ablation procedures (CPT 93651) was not specific for AF ablation (there is no CPT code specifically for curative AF ablation procedures). The study may therefore have inadvertently captured AF patients undergoing ablation for other supraventricular tachycardias, although our exclusion of patients with ICD-9-CM diagnosis codes for paroxysmal supraventricular tachycardia and other supraventricular tachycardias makes this unlikely. Ablation success rate was determined indirectly, being defined in terms of freedom from antiarrhythmic drug therapy rather than freedom from arrhythmia recurrence, which can only be established by electrocardiogram monitoring. Given that elderly patients are likely to remain on antiarrhythmic drugs for precautionary reasons following AF ablation, ${ }^{26}$ the study potentially underestimates the effectiveness of catheter ablation in restoring and maintaining sinus rhythm in this 
population. Moreover, in the context of the current "hybrid" (ie, combined pharmacologic and nonpharmacologic) treatment approach to $\mathrm{AF}^{40}$ continuation of antiarrhythmic drug therapy need not equate with ablation failure. It is conceivable that an ablation procedure, while failing to eradicate the electrophysiologic substrate for AF, might nevertheless facilitate subsequent pharmacologic cardioversion. At the same time, the study has the potential to overestimate AF ablation success rate, since the absence of antiarrhythmic therapy might instead be due to adoption of a rate-control approach. In addition, the rate of repeat ablation (5\%) in this patient sample was considerably lower than that expected, suggesting possible patient selection bias. The study data were collected over a 12-month follow-up period, and the results should not be extrapolated beyond this time frame. Additionally, it should be borne in mind that the database was restricted to patients with Medicare supplemental insurance, who may not necessarily be representative of all Medicare beneficiaries with AF. Finally, the analysis took into account only the direct costs associated with AF ablation and the medical management of AF: no information was provided on complications associated with the ablation procedure or on AF-associated complications such as heart failure and stroke, and their likely impact on overall costs. With continuing growth in the use of catheter ablation for AF among the Medicare-aged population, the risk of clinical complications (particularly perforation, cardiac tamponade, and vascular access problems) can be expected to become an increasingly important consideration in this age-group..$^{39}$ Despite these limitations, the study nevertheless provides useful insight into "real-world" practice among the Medicare-aged population until such time as the CABANA trial findings become available.

\section{CONCLUSION}

In the "real-world" (nonclinical-trial) setting, use of catheter ablation for second-line treatment of AF proved successful in $~ 50 \%$ of this limited sample of Medicare-aged patients. Overall, the annualized cost per patient of medical management of AF (ablation plus other AF-related services) was substantial, and tended to be higher in patients with failed ablation than in those with successful ablation $(\$ 19,997$ vs. $\$ 16,049 ; P=0.07)$. This differential appeared to be due in part to the significantly higher pharmacy and outpatient costs incurred following ablation failure. However, in view of the small sample size and the inherent limitations of a claims-based analysis, caution is required in extrapolating these costs findings to the Medicare-aged $\mathrm{AF}$ ablation population as a whole.

\section{ACKNOWLEDGMENTS}

Financial and editorial support for development of this manuscript has been provided by sanofi-aventis US, Inc. Dr. Kim is a research consultant to sanofi-aventis, has served on advisory boards for sanofi-aventis, and is a member of the sanofi-aventis speakers bureau. At the time of the study, Dr. Lin was an employee of sanofi-aventis, and Mr. Kreilick and Ms. Foltz Boklage were employees of ProUnlimited, which has a research consulting agreement with sanofi-aventis. Acknowledgement is due to Mehul Dalal of sanofi-aventis for his thoughtful review of the draft manuscript. Editorial support was provided by Andrew Fitton, PhD, of UBC Scientific Solutions.

Open Access. This article is distributed under the terms of the Creative Commons Attribution Noncommercial License which permits any noncommercial use, distribution, 
and reproduction in any medium, provided the original author(s) and source are credited.

\section{REFERENCES}

1. Naccarelli GV, Varker H, Lin J, Schulman KL. Increasing prevalence of atrial fibrillation and flutter in the United States. Am J Cardiol. 2009;104:1534-1539.

2. Feinberg WM, Blackshear JL, Laupacis A, Kronmal R, Hart RG. Prevalence, age distribution, and gender of patients with atrial fibrillation. Analysis and implications. Arch Intern Med. 1995;155:469-473.

3. Go AS, Hylek EM, Phillips KA, et al. Prevalence of diagnosed atrial fibrillation in adults: national implications for rhythm management and stroke prevention: the AnTicoagulation and Risk Factors in Atrial Fibrillation (ATRIA) Study. J Am Med Assoc. 2001;285:2370-2375.

4. Stewart S, Hart CL, Hole DJ, McMurray JJ. A population-based study of the long-term risks associated with atrial fibrillation: 20-year followup of the Renfrew/Paisley study. Am J Med. 2002;113:359-364.

5. Wolf PA, Abbott RD, Kannel WB. Atrial fibrillation: a major contributor to stroke in the elderly. The Framingham Study. Arch Intern Med. 1987;147:1561-1564.

6. Miyasaka Y, Barnes ME, Gersh BJ, et al. Changing trends of hospital utilization in patients after their first episode of atrial fibrillation. Am J Cardiol. 2008;102:568-572.

7. Wattigney WA, Mensah GA, Croft JB. Increased atrial fibrillation mortality: United States, 19801998. Am J Epidemiol. 2002;155:819-826.

8. Wattigney WA, Mensah GA, Croft JB. Increasing trends in hospitalization for atrial fibrillation in the United States, 1985 through 1999: implications for primary prevention. Circulation. 2003;108:711716.

9. Coyne KS, Paramore C, Grandy S, Mercader M, Reynolds M, Zimetbaum P. Assessing the direct costs of treating nonvalvular atrial fibrillation in the United States. Value Health. 2006;9:348-356.

10. Kim M, Lin J, Hussein M, Kreilick C, Battleman D. Cost of atrial fibrillation in United States managed care organizations. Adv Ther. 2009;26:847-857.

11. Fuster V, Rydén LE, Cannom DS, et al. ACC/ AHA/ESC 2006 guidelines for the management of patients with atrial fibrillation: full text: a report of the American College of Cardiology/American
Heart Association Task Force on practice guidelines and the European Society of Cardiology Committee for Practice Guidelines (Writing Committee to Revise the 2001 guidelines for the management of patients with atrial fibrillation) developed in collaboration with the European Heart Rhythm Association and the Heart Rhythm Society. Europace. 2006;8:651-745.

12. Chugh A, Morady F. Atrial fibrillation: catheter ablation. J Interv Card Electrophysiol. 2006; $16: 15-26$

13. Lubitz SA, Fischer A, Fuster V. Catheter ablation for atrial fibrillation. Brit Med J. 2008;336:819-826.

14. Nair GM, Nery PB, Diwakaramenon S, Healey JS, Connolly SJ, Morillo CA. A systematic review of randomized trials comparing radiofrequency ablation with antiarrhythmic medications in patients with atrial fibrillation. J Cardiovasc Electrophysiol. 2009;20:138-144.

15. Goldberg A, Menen M, Mickelsen $S$, et al. Atrial fibrillation ablation leads to long-term improvement of quality of life and reduced utilization of healthcare resources. J Interv Card Electrophysiol. 2003;8:59-64.

16. Weerasooriya R, Jaïs P, Le Heuzey JY, et al. Cost analysis of catheter ablation for paroxysmal atrial fibrillation. Pacing Clin Electrophysiol. 2003;26:292-294.

17. Gerstenfeld EP, Callans D, Dixit S, et al. Characteristics of patients undergoing atrial fibrillation ablation: trends over a seven-year period 1999-2005. J Cardiovasc Electrophysiol. 2007;18:23-28.

18. Ye $\mathrm{X}$, Gross CR, Schommer J, Cline $\mathrm{R}$, Xuan J, St Peter WL. Initiation of statins after hospitalization for coronary heart disease. J Man Care Pharm. 2007;13:385-396.

19. Zhou F, Harpaz R, Jumaan AO, Winston CA, Shefer A. Impact of varicella vaccination on health care utilization. J Am Med Assoc. 2005; 294:797-802.

20. Calkins H, Brugada J, Packer DL, et al. HRS/ EHRA/ECAS expert consensus statement on catheter and surgical ablation of atrial fibrillation: recommendations for personnel, policy, procedures and follow-up. A report of the Heart Rhythm Society (HRS) Task Force on Catheter and Surgical Ablation of Atrial Fibrillation developed in partnership with the European Heart Rhythm Association (EHRA) and the European Cardiac Arrhythmia Society (ECAS); in collaboration with the American College of Cardiology (ACC), American Heart Association (AHA), and the Society 
of Thoracic Surgeons (STS). Endorsed and approved by the governing bodies of the American College of Cardiology, the American Heart Association, the European Cardiac Arrhythmia Society, the European Heart Rhythm Association, the Society of Thoracic Surgeons, and the Heart Rhythm Society. Europace. 2007;9:335-379.

21. Bhargava M, Marrouche NF, Martin DO, et al. Impact of age on the outcome of pulmonary vein isolation for atrial fibrillation using circular mapping technique and cooled-tip ablation catheter: a retrospective analysis. J Cardiovasc Electrophysiol. 2004;15:8-13.

22. Corrado A, Patel D, Riedlbauchova L, et al. Efficacy, safety, and outcome of atrial fibrillation ablation in septuagenarians. J Cardiovasc Electrophysiol. 2008;19:807-811.

23. Hsieh $\mathrm{MH}$, Tai CT, Lee $\mathrm{SH}$, et al. Catheter ablation of atrial fibrillation versus atrioventricular junction ablation plus pacing therapy for elderly patients with medically refractory paroxysmal atrial fibrillation. J Cardiovasc Electrophysiol. 2005;16:457-461.

24. Kusumoto F, Prussak K, Wiesinger M, Pullen T, Lynady C. Radiofrequency catheter ablation of atrial fibrillation in older patients: outcomes and complications. J Interv Card Electrophysiol. 2009;25:31-35.

25. Traub D, Daubert JP, McNitt S, Zareba W, Hall B. Catheter ablation of atrial fibrillation in the elderly: where do we stand? Cardiol J. 2009;16:113-120.

26. Zado E, Callans DJ, Riley $M$, et al. Long-term clinical efficacy and risk of catheter ablation for atrial fibrillation in the elderly. J Cardiovasc Electrophysiol. 2008;19:621-626.

27. Cappato R, Calkins H, Chen SA, et al. Worldwide survey on the methods, efficacy, and safety of catheter ablation for human atrial fibrillation. Circulation. 2005;111:1100-1105.

28. Cheema A, Dong J, Dalal D, et al. Long-term safety and efficacy of circumferential ablation with pulmonary vein isolation. J Cardiovasc Electrophysiol. 2006;17:1080-1085.

29. Mainigi SK, Sauer WH, Cooper JM, et al. Incidence and predictors of very late recurrence of atrial fibrillation after ablation. J Cardiovasc Electrophysiol. 2007;18:69-74.

30. Shah AN, Mittal S, Sichrovsky TC, et al. Longterm outcome following successful pulmonary vein isolation: pattern and prediction of very late recurrence. J Cardiovasc Electrophysiol. 2008;19:661-667.

31. Cappato R, Negroni S, Pecora D, et al. Prospective assessment of late conduction recurrence across radiofrequency lesions producing electrical disconnection at the pulmonary vein ostium in patients with atrial fibrillation. Circulation. 2003;108:1599-1604.

32. Chugh A, Oral H, Lemola K, et al. Prevalence, mechanisms, and clinical significance of macroreentrant atrial tachycardia during and following left atrial ablation for atrial fibrillation. Heart Rhythm. 2005;2:464-471.

33. Gerstenfeld EP, Callans DJ, Sauer W, Jacobson J, Marchlinski FE. Reentrant and nonreentrant focal left atrial tachycardias occur after pulmonary vein isolation. Heart Rhythm. 2005;2:1195-1202.

34. Oral H, Knight BP, Ozaydin M, et al. Clinical significance of early recurrences of atrial fibrillation after pulmonary vein isolation. J Am Coll Cardiol. 2002;40:100-104.

35. Andrikopoulos G, Tzeis S, Maniadakis N, Mavrakis HE, Vardas PE. Cost-effectiveness of atrial fibrillation catheter ablation. Europace. 2009;11:147-151.

36. Khaykin Y, Morillo CA, Skanes AC, McCracken A, Humphries K, Kerr CR. Cost comparison of catheter ablation and medical therapy in atrial fibrillation. J Cardiovasc Electrophysiol. 2007;18:907-913.

37. Khaykin Y, Wang X, Natale A, et al. Cost comparison of ablation versus antiarrhythmic drugs as first-line therapy for atrial fibrillation: an economic evaluation of the RAAFT pilot study. J Cardiovasc Electrophysiol. 2009;20:7-12.

38. Reynolds MR, Zimetbaum P, Josephson ME, Ellis E, Danilov T, Cohen DJ. Cost-effectiveness of radiofrequency catheter ablation compared with antiarrhythmic drug therapy for paroxysmal atrial fibrillation. Circ Arrhythm Electrophysiol. 2009;2:362-369.

39. Ellis ER, Culler SD, Simon AW, Reynolds MR. Trends in utilization and complications of catheter ablation for atrial fibrillation in Medicare beneficiaries. Heart Rhythm. 2009;6:1267-1273.

40. Govindan M, Catanchin A, Camm AJ. The place of hybrid therapies with drugs to supplement nonpharmacological therapies in atrial fibrillation. J Cardiovasc Pharmacol. 2008;52:210-221. 